(c)

(i) ${ }_{\mathrm{Br}}$

$\ominus$ ND

(5) Nc

\title{
EL PODER BLANDO EN LA GLOBALIZACIÓN: ALGUNOS ASPECTOS DE LA COMUNICACIÓN EN EL SISTEMA INTERNACIONAL
}

\section{Soft Power in Globalization: Some Aspects of Communication within the International System}

O poder brando na globalização: alguns aspectos da comunicação no sistema internacional

RECIBIDO:23 DE OCTUBRE DE 2013

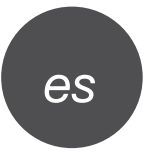

\section{RESUMEN}

Se abordan algunos aspectos esenciales sobre las comunicaciones que afectan el funcionamiento del sistema internacional en la globalización. Se analizan las fuentes de donde emana el ejercicio del "poder blando" en el ámbito global. Entre dichas fuentes se encontrarían el surgimiento de una cultura global y el control de los flujos de comunicación y la información por parte de los actores más importantes del sistema internacional. Por tanto, se indaga en las causas del auge de las comunicaciones y sus consecuencias más importantes para el funcionamiento del sistema internacional.
EVALUADO:20 DE MAYO DE 2014

Aleksandro Palomo Garrido (México)

Doctor en Ciencias Políticas

Universidad de Colima

Facultad de Ciencias Políticas palomo@ucol.mx

\section{en}

\section{ABSTRACT}

This article presents some essential aspects of the communications that affect the international system functioning within globalization. We analyzed sources where the exercise of "soft power" appears worldwide. Among such sources, there is the emergence of a global culture as well as the flow of communication and information from the most important actors of the international system. Therefore, we researched on the reasons for communication growth and its most important consequences for the functioning of the international system.
PALABRAS CLAVE: globalización, proceso de globalización, sector de las comunicaciones, poder blando, cultura global.
KEYWORDS: Globalization, globalization process, communication sector, soft power, global culture.
ACEPTADO:28 DE JUNIO DE 2014

\section{RESUMO}

Abordam-se alguns aspectos essenciais sobre as comunicações que afetam o funcionamento do sistema internacional na globalização. Analisam-se as fontes de onde emana o exercício do "poder brando" no âmbito global. Entre ditas fontes se encontrariam o surgimento de uma cultura global e o controle dos fluxos de comunicação e a informação da parte dos atores mais importantes do sistema internacional. Por tanto, se indaga nas causas do auge das comunicações e as suas consequências mais importantes para o funcionamento do sistema internacional.

PARA CITAR ESTE ARTÍCULO/TO CITE THIS ARTICLE/PARA CITAR ESTE ARTIGO: 


\section{INTRODUCCIÓN}

Este artículo aborda la disputa por ejercer el "poder blando" en el periodo histórico de la globalización desde la óptica de las relaciones internacionales. A lo largo del texto, se pretende exponer todos los factores que confluyen en el ejercicio del poder blando en el ámbito global y describir su desarrollo histórico para identificar las variables que interactúan en el ejercicio de dicho poder. Esta identificación de las variables que conforman el poder blando se plantea como indispensable, ya que el concepto y sus consecuencias se han empleado con frecuencia en el estudio de las relaciones internacionales, pero no tan a menudo se han indagado sobre las fuentes de donde emana dicho poder.

El análisis queda enmarcado dentro del periodo de la globalización. Se tratará de establecer un desarrollo histórico coherente con los factores que han influido en el ejercicio del poder blando en el ámbito global hasta la actualidad. La hipótesis planteada es que el surgimiento de un sistema internacional más interconectado e interdependiente ha sentado las bases para el ejercicio del poder blando a una escala mayor. Los canales de intercambio y difusión por donde fluye el poder blando son más nutridos que nunca y tienen un alcance mayor. Por tanto, la globalización es el escenario perfecto para el desenvolvimiento del poder blando a escala planetaria.

Para establecer un adecuado marco teórico, en primer lugar, definiremos muy claramente el concepto de globalización. La versatilidad de este término ha generado confusión. Desde la perspectiva de este artículo, se considerará la globalización como un periodo histórico. Su principal característica es la interdependencia que se ha desarrollado en el planeta en las últimas décadas, debido al desarrollo de las tecnologías de la comunicación.

Desde nuestro punto de vista, delimitaremos el periodo histórico de la globalización como el inmediatamente anterior al de la guerra fría, y que es en el que nos hallamos actualmente inmersos. Por ello, debemos ajustar su origen al final de la guerra fría, es decir, al comienzo de la distensión originada por la Perestroika. Tomaremos como referencia simbólica la caída del
Muro de Berlín en 1989, que marca el inicio de los acontecimientos que llevan hasta la desaparición de la Unión Soviética en 1991 (Palomo, 2012)1.

También distinguiremos entre el concepto de globalización y el de proceso de globalización. Nos referiremos al proceso de globalización como el conjunto de cambios que caracterizan su actual desarrollo histórico. Consideraremos este proceso de globalización como un proceso evolutivo económico, político y social que se desarrolla en el periodo histórico de la globalización. En este proceso evolutivo, confluye la acción de los diferentes actores globales que interactúan en una dinámica molecular en la que surgen focos de actividad, normalmente en torno a grandes ciudades ${ }^{2}$, que son centros de producción o distribución y que están conectados entre sí por las modernas vías de comunicación. Esta dinámica de interconexión provoca fuerzas múltiples que se entrecruzan, a veces contrarrestándose y otras reforzando tendencias conjuntas. El proceso de globalización tiende a expandirse por diferentes dinámicas internas (Harvey, 2007): unas son de tipo económico, por cuanto generan demanda de inversión y consumo y beneficios económicos, y otras son de tipo social y político, por efecto contagio e imitación de otros modelos de desarrollo "más exitosos" o por asimilación forzosa.

La dinámica de este proceso de globalización ha generado una reestructuración de la producción. También transformaciones en la estructura social internacional fruto de la reestructuración de la producción y de los nuevos avances tecnológicos (Castells, 2001a). A través de redes de todo tipo se han conectado lugares, sociedades e individuos de todo el mundo, con lo cual se ha producido un crecimiento considerable de la interacción social en el mundo (Ramonet, 1997). Estos avances tecnológicos tuvieron consecuencias decisivas sobre los medios de comunicación. Por un lado, incrementó la cantidad de información que se podía difundir empleando la misma infraestructura (Barbier y Bertho, 1996). Por ejemplo, la tecnología digital aplicada a las comunicaciones permitía que pudiera circular un número casi infinito de canales de televisión por una

1 Para un desarrollo más extenso del marco teórico, se recomienda consultar Palomo (2018). 2 Sassen (2010, p. 36) las cifra en torno a 40 ciudades en todo el mundo.
. 
misma red. Por otro lado, la velocidad de transmisión de la información se multiplicó rápidamente. Al mismo tiempo, el acceso a las telecomunicaciones se generalizó entre la población. Una causa de esto era que los costes de transmisión en la globalización eran insignificantes comparados con el pasado. Por tanto, la cantidad de información que se podía transmitir al mundo entero era casi infinita. El resultado fue una explosión de la información global.

El ejemplo paradigmático de todo esto es la irrupción de internet en el panorama global. Diseñado en la década de 1960 como una red de vinculación con objetivos militares y más tarde científicos, internet pasó a ser un medio de comunicación entre individuos y marcó un momento histórico en la década de 1990 cuando comenzó a expandirse su uso. El desarrollo de la web en 1990 modificó las condiciones de acceso a la información y permitió a cualquier individuo un acceso sencillo a la información almacenada y enviar mensajes ${ }^{3}$. En 1993 ya había una red de 50 sitios web en todo el mundo. Al terminar la década, la cifra superaba los 5 millones (Nye, 2003, p. 73). En 1994 el primer navegador aceleró la velocidad del tráfico y poco a poco los buscadores se hicieron más precisos. Finalmente, las conexiones de alto rendimiento permitieron transferencias de datos cada vez más voluminosas. La última innovación incorporada fue el acceso a través de los teléfonos móviles.

El caso de los teléfonos móviles es el otro paradigma de la comunicación en la globalización. En 1990 había 11 millones de usuarios abonados a la telefonía móvil en el mundo y 2.6 millones de usuarios de internet. Ya en 2002 eran 1000 millones los abonados a la telefonía móvil y 500 millones los usuarios de internet (Held y McGrew, 2011, p. 45). Este cambio espectacular de las tecnologías de la informática y las comunicaciones se consideró como una tercera revolución industrial. Sus consecuencias no fueron menores. En lo social transformó la conducta de los individuos en su forma de comunicarse. En lo político y económico afectó la forma de actuar de los Gobiernos, a la soberanía nacional, a la

3 Los principales Estados con mayor número de usuarios de internet en 1999 eran los Estados Unidos, Japón, el Reino Unido, Canadá, Alemania, Australia, Brasil, China (Held y McGrew, 2011, p. 46). forma de hacer negocios, favoreció el incremento de los poderes no estatales, etc. En concreto, nos centraremos en la articulación del ejercicio del poder blando en el ámbito global (Nye, 2003).

No debemos olvidar que la aplicación de esta revolución tecnológica tuvo dimensiones globales, gracias a la desregulación de las actividades del sector industrial de las comunicaciones. A continuación, vamos a analizar más en profundidad el acontecer histórico de la desregulación del sector de las comunicaciones en el ámbito global. Este hecho, junto con el desarrollo tecnológico de las comunicaciones, sería la causa principal en el surgimiento de un espacio global para la difusión de la información. También analizaremos como uno de los factores de incidencia más directos sobre el ejercicio del poder blando el proceso de concentración industrial que se inicia en el sector. Más adelante, examinaremos algunas de las consecuencias más importantes para el funcionamiento del sistema internacional, originadas por el surgimiento del espacio global de la información. En concreto, centraremos nuestra atención en el surgimiento de una cultura global y en el ejercicio del poder blando, que puedan hacer valer los gobiernos de las grandes potencias con el uso de la cultura y la información (Arrighi, 2007).

\section{LA DESREGULACIÓN DEL SECTOR DE LAS TELECOMUNICACIONES}

Podemos distinguir tres grandes sectores industriales relacionados con la industria de las comunicaciones: 1) el sector mediático dedicado principalmente a los medios de comunicación y a la producción de contenidos para el entretenimiento y la información ${ }^{4}$; 2) el de las telecomunicaciones, encargado del abastecimiento de las infraestructuras y los servicios relacionados con la comunicación ${ }^{5}$, y 3 ) el de la informática, relacionado con

\footnotetext{
4 Las principales corporaciones del sector en medios de comunicación y contenidos son Sony, Walt Disney, Comcast, Amazon, News Corp, Google, Time Warner, DirecTV, Maruhan y Bertelsmann.

5 Las principales corporaciones en servicios de telecomunicaciones mundiales son NTT, AT\&T, Deutsche Telekom, Vodaphone, BT, France Telecom, Telecom Italia, Verizon, Telefónica, China Mobile. En cuanto a proveedores de equipos de telecomunicaciones destacan Nokia, Cisco, Ericsson, Samsung, Huawei, Alcatel Lucent, Motorola, Nokia Siemens Networks, LG, NEC.
} 
el software y el hardware de los equipos informáticos ${ }^{6}$. A pesar de diferenciar estas tres ramas de actividad, el uso de las tecnologías, a menudo, es común para las tres. Además, con frecuencia, las corporaciones del ramo operan en los tres sectores, y mantienen departamentos especializados (Kishan, 2009).

La industria de las comunicaciones experimentó un importante crecimiento en la globalización. Se pueden distinguir dos causas de este crecimiento. Por un lado, el desarrollo de la tecnología permitió la convergencia de las innovaciones tecnológicas en la informática y las telecomunicaciones, lo cual favoreció la masiva distribución de información a escala global. Nunca tal cantidad de información había estado disponible tan fácilmente y de manera casi gratuita. Por lo que se habló, en la globalización, de la sociedad global de la información. La otra causa fue la desregulación masiva de las telecomunicaciones en el mundo entero, lo cual aceleró y facilitó la circulación de la información.

Como en los otros sectores industriales, la desregulación del sector de las comunicaciones se inició en la década de 1980 con las primeras políticas neoliberales. Desde la guerra fría, la Organización de las Naciones Unidas para la Educación, la Ciencia y la Cultura (Unesco) venía apoyando la aplicación del nuevo orden mundial de la información y la comunicación (Nomic), plan que pretendía evitar el desequilibrio en el flujo de información entre el centro y la periferia ${ }^{7}$. Sin embargo, Washington impugnó este plan en 1981 alegando que interfería con el libre mercado al dotar de amplios poderes a los Gobiernos. La pugna de los Estados Unidos con la Unesco culminó en 1984 cuando abandonó el organismo internacional. A continuación, el Reino Unido imitó su postura y, al poco tiempo, el Nomic fue abandonado por falta de presupuesto y de iniciativa por el resto de integrantes de la Unesco. A partir de entonces, los intercambios de bienes culturales

6 Las principales corporaciones del sector en servicios informáticos y software son IBM, Microsoft, HP, Oracle, Fujitsu, Accenture, CSC, SAP, NEC, Hitachi. En equipos informáticos y proveedores de servicios son HP, Toshiba, Hon Hai, Dell, NEC, Apple, Qanta Computer, ASUS, Acer, Compal electronics.

7 Cuanto más pobres y débiles son los Estados, más dependen de la reproducción de noticias provenientes de las agencias de noticias. Por ejemplo, en Europa la dependencia oscila entre 40 y $70 \%$ de las noticias publicadas, mientras que en África no disminuye de $80 \%$ (Borreguero, 2007, p. 35). y la comunicación internacional pasaron a ser un asunto tratado como el resto de los intercambios comerciales.

En concreto, pasaron a tratarse en el seno de las negociaciones de la Ronda Uruguay del Acuerdo General sobre Comercio y Aranceles (GATT) hasta 1993. Las discusiones en el GATT fueron un enfrentamiento abierto entre la Unión Europea y los Estados Unidos por el ámbito audiovisual. La falta del acuerdo residía en que la Unión Europea se negaba a considerar las creaciones culturales y artísticas como productos susceptibles del mismo trato que el resto del intercambio comercial, e incluibles, por tanto, dentro de los acuerdos comerciales de intercambio convencionales. Por su parte, los Estados Unidos defendían el abandono total de las medidas de protección a favor del libre cambio. La postura de los Estados Unidos venía respaldada por su preeminencia en el mercado audiovisual ${ }^{8}$.

La falta de acuerdo en esta materia llegó a bloquear las negociaciones de la Ronda Uruguay, por lo que, finalmente, se reconoció el concepto de excepción cultural, que defendía la Unión Europea, y se apartó el sector de las comunicaciones de las negociaciones del GATT. Según este concepto, los bienes y servicios culturales participan de la identidad cultural de los Estados y manifiestan la diversidad creadora de los individuos. Por tanto, son incomparables a otras mercancías y merecen un tratamiento diferente del mercantil habitual. Una vez rechazado el consenso en el GATT, la discusión se trasladó a la recién formada Organización Mundial del Comercio (OMC). La negativa de los Estados europeos a firmar un acuerdo de libre intercambio en el sector fue objeto de duras críticas por parte de los Estados Unidos, que veía en esto un atentado contra el libre comercio y un proteccionismo encubierto de la industria europea 9 . En cambio, la Unión Europea se aferraba a la excepción

8 El déficit comercial de la Unión Europea era clamoroso. El 69 \% de los programas de ficción de televisión importados entre 1994 y 1995 por 88 cadenas de televisión europeas procedían de los Estados Unidos. Además, 70 \% de la recaudación en cines de Europa lo hacían las productoras estadounidenses (Mattelart, 1998, p. 90).

9 En realidad, aunque los Estados Unidos no imponen aranceles a estas importaciones, limita la difusión de los productos importados con actitudes como no doblar al inglés las películas en lengua extranjera, lo cual limita mucho su audiencia y posible difusión; o unos códigos morales de censura que sancionan a las películas extranjeras más severamente y las limitan a un circuito marginal de exhibición y difusión. Además, realiza dumpin, con lo cual inunda el mercado de cine de baja calidad, y sobre todo de TV, a precios más baratos, que apenas cubren los costes, pero que aniquilan la competencia y desaniman la producción nacional de los demás países. 
cultural que se formuló para excluir los bienes y servicios culturales de los acuerdos de libre cambio.

En diciembre de 1996, la OMC decidió en Singapur la liberalización del mercado de los servicios de telecomunicaciones (telefonía, telefonía móvil, radio, televisión, etc.), y 68 países firmaban, en febrero de 1997, el acuerdo en Ginebra. Este proceso de desregulación significó la privatización de numerosas empresas públicas que monopolizaban el sector, la derogación de leyes que imponían restricciones a la iniciativa privada en las comunicaciones y el surgimiento de un competitivo mercado de dimensiones globales. Sin embargo, en 2010, la discusión acerca del intercambio comercial de bienes culturales seguía postergada indefinidamente en el seno de la OMC. La Ronda Doha, que se había iniciado en 2001, se centró durante toda la década posterior en la reforma de los subsidios agrícolas, la mejora del acceso a los mercados mundiales y la necesidad de un crecimiento económico sostenible en los Estados de la periferia, por lo que no se prestó atención al intercambio de bienes culturales y no hubo un progreso en las negociaciones.

Por su parte, la Unión Europea logró revitalizar la discusión en la Unesco, donde se inició un proceso para desarrollar un instrumento que garantizase la defensa internacional de la diversidad cultural. Los Estados Unidos también participaron en las discusiones, ya que se habían reincorporado, en 2003, a la Unesco. Este proceso culminó con la aprobación de la Convención sobre la Diversidad Cultural en 2005, con los votos en contra de los Estados Unidos e Israel. Este acuerdo salvaguardaba la acción de los Estados para promover, proteger y defender su patrimonio cultural y lingüístico frente a otros Estados. Hasta 2010 la Convención fue ratificada por un centenar de Estados. A causa de la ratificación de la Convención, la diversidad cultural se ha convertido en uno de los ejes centrales de actuación que tienen las políticas culturales nacionales en la actualidad. Sin embargo, este código de conducta de la Unesco no tiene la fuerza contractual que poseen los acuerdos de la OMC. Por lo que los Estados Unidos han podido firmar tratados bilaterales comerciales que limitan el ámbito de las políticas culturales nacionales con numerosos Estados.

\section{LA CONCENTRACIÓN INDUSTRIAL DEL SECTOR DE LAS COMUNICACIONES}

Por otro lado, las corporaciones del sector de la comunicación no fueron ajenas al proceso de concentración industrial impulsado por el proceso de globalización (Sparks, 2009). En su competencia por abarcar mayores cuotas de mercado, las corporaciones mediáticas se hicieron más grandes y diversificaron sus negocios. A partir de la década de 1990, con la desregulación del sector de las comunicaciones, se produjo una diversificación de las inversiones con una tendencia a crear grandes corporaciones multimedia que abarcaban varios ámbitos relacionados con las comunicaciones. A partir de 2000, se inició un nuevo proceso en el que los grupos multimedia tradicionales comenzaron a fusionarse o a absorber también a corporaciones del ámbito de internet, ya que las corporaciones veteranas comenzaron a percibir internet como un nuevo campo para ampliar su mercado. Esta tendencia tuvo como resultado una convergencia corporativa y de mercados, que resultó en una aproximación entre la industria mediática, la de telecomunicaciones y la informática. De manera que el sector ha experimentado uno de los procesos de concentración más acusados de toda la industria.

La concentración industrial mediática estuvo liderada por los Estados Unidos tanto por el hecho de poseer el principal conglomerado industrial como por ser pionero en la desregulación del sector. Desde la década de 1980, los sucesivos Gobiernos habían empezado el desmantelamiento de las leyes antimonopolio, con la excusa de mejorar la competitividad de las corporaciones nacionales frente a las japonesas. Las fusiones y absorciones producidas a lo largo de la globalización convirtieron el sector de las comunicaciones en uno de los más concentrados de la economía estadounidense. La correspondiente concentración industrial en Europa fue muy posterior a la de los Estados Unidos, debido a la desregulación más tardía del sector.

Ya en 1989 el grupo editorial Time compró Warner, uno de los principales estudios cinematográficos. En los siguientes años, las corporaciones mediáticas también asaltaron el espacio de las plataformas de TV por cable y satélite. Por ejemplo, en 1996, Time-Warner 
absorbió Turner Broadcasting, entonces el segundo operador por cable, uno de los primeros programadores y dueño además de CNN. En 1995 Disney adquirió Capital Cities y fue añadiendo otras empresas como Pixar, ABC, Disney Channel, ESPN, History Channel, E! Entertainment, Buena Vista, Touchstone Pictures, Hollywood Records, etc. También, en 1995, se fusionó Viacom ${ }^{10}$ con $\mathrm{CBS}^{11}$; sin embargo, debido a la crisis puntocom, la corporación se dividió de nuevo en 2004 en dos corporaciones. En 2000 Time-Warner protagonizó la mayor fusión del sector, hasta la fecha, con America Online (AOL), que era un proveedor de recursos de internet. La nueva corporación, AOL-TW poseía CNN, TNT, Cartoon Network, HBO, Warner Bros, Hanna Barbera, Castle Rock, New Line Cinema, Fortune, Life, People, etc. Sin embargo, a finales de 2009, se produjo de nuevo la escisión entre las dos corporaciones.

Paradójicamente, en este mercado donde el lema ensalzado es la libertad de comercio, se daba una situación de control absoluto, donde continuamente se cerraban fusiones entre corporaciones. Solo en Europa hubo 895 fusiones en 1993. En el ámbito global, las fusiones en el área de las comunicaciones han dado lugar a unas macrocorporaciones que controlan prácticamente toda la información que circula por el mundo. Así surgen estos grandes emporios que han transformado la industria de las telecomunicaciones, la cual ha experimentado un gran crecimiento y se ha transformado en una de las más poderosas, con consecuencias sociales trascendentes y responsabilidades mínimas ${ }^{12}$. En 2000 la crisis puntocom golpeó duramente, sobre todo, a los negocios relacionados con internet. Sin embargo, la vitalidad del sector contribuyó a una rápida recuperación económica.

La desregulación y liberalización del mercado de las comunicaciones favoreció las corporaciones estadounidenses que son las más poderosas. Podemos observar que la lista de las corporaciones de comunicaciones más potentes del mundo es una lista de compañías con

10 Viacom gestiona Dreamworks, Paramount, VH-1, MTV, Nickelodeon, Showtime, etc.

11 Por su parte, CBS agrupa a CBS, Paramount Home, King World Productions, Simon\&Schuster, etc.

12 Las corporaciones financieras son uno de los principales accionistas de las corporaciones mediáticas (Collon, 1996, p. 134). titularidad estadounidense. El dominio del mercado de las comunicaciones por los Estados Unidos es total. En 2010 la industria estadounidense de la comunicación facturó 1.12 billones de dólares. A pesar de que la tecnología de la información representaba solo $8.3 \%$ de la economía estadounidense en 2000, constituía un tercio de todo el aumento de la productividad entre 1995 y 1999 (Nye, 2003, p. 177). Además, el ritmo de crecimiento del sector está por encima del crecimiento medio de la economía estadounidense. Solamente el sector audiovisual tuvo un superávit comercial de 11700 millones de dólares o $7 \%$ del total del superávit experimentado por el sector de los servicios en 2008 en los Estados Unidos (Crusafon, 2012, pp. 63-64).

Tan solo en el sector de las telecomunicaciones es donde el liderazgo estadounidense ha sido superado en los últimos años. Las dos principales corporaciones en cuanto al despliegue e implantación de la banda ancha son chinas: China Telecom y China Unicom. Las siguen a distancia NTT (Japón), KT Corp (Corea del Sur), Comcast, AT\&T, Time Warner y Verizon (EE.UU.), Deutsche Telekom (Alemania), France Telecom (Francia). Lo mismo ocurre con la telefonía móvil. Las corporaciones chinas e indias lideran la clasificación en cuanto a número de clientes. Las grandes poblaciones de estos Estados, junto con el rápido ritmo de adopción de las nuevas tecnologías, han convertido a estas corporaciones en las más importantes del mundo. China Mobile tenía en 2010 más de 600 millones de abonados. En la India cuatro corporaciones se dividen el mercado con un número de abonados entre los 100 y 180 millones (Crusafon, 2012, p. 128). Estas corporaciones pueden protagonizar en el futuro un importante salto hacia los mercados internacionales.

\section{LA CULTURA GLOBAL}

El intercambio de productos culturales se convirtió en un poderoso motor económico durante la globalización. En 1998 las importaciones globales de productos culturales ascendían a 213655 millones de dólares (Held y McGrew, 2011, p. 48). Desde comienzos de la globalización hubo un profundo cambio estructural en la importancia relativa de las diferentes categorías del comercio cultural. Aunque los bienes musicales seguían 
dominando el mercado y representaban un cuarto de todas las importaciones y exportaciones culturales, hubo un incremento notable en la producción de bienes deportivos y juegos. Se mantuvo la estabilidad relativa en libros, otros materiales impresos y receptores de radio y televisión. En cuanto a los productos cinematográficos, fotográficos y las artes visuales hubo un declive constante (Held y McGrew, 2011, p. 48), mientras que el sector de los videojuegos experimentó un boom espectacular ${ }^{13}$.

El papel de la industria de las comunicaciones en esta tarea de difusión de la cultura es de capital importancia (Barker, 2003). Sin duda, las grandes corporaciones globales de la comunicación son los actores hegemónicos de la oferta cultural global. Las grandes corporaciones dedicadas al negocio multimedia distribuyen en el mercado mundial una cantidad cada vez mayor de productos culturales destinados a un público cada vez más amplio. Desde la década de 1990 el desarrollo de las tecnologías y la aplicación de las políticas de desregulación han permitido una internacionalización y una enorme concentración del sector que está dominado por las corporaciones estadounidenses. Por ejemplo, las corporaciones de Hollywood controlan $85 \%$ del mercado cinematográfico mundial, entre las que destacan Metro Goldwyn Mayer-United Artists, Disney, Paramount, $20^{\text {th }}$ Century Fox y AOL-TW. En el mercado de la música, este está controlado, en más de $80 \%$, por cuatro grandes corporaciones: Universal, Sony-BMG, EMI y Warner (Crusafon, 2012, p. 64).

Este efervescente negocio impulsó un debate mundial sobre la protección de la cultura. Los Estados mantuvieron posiciones divergentes en torno al debate. Algunos patrocinaban la creación cultural propia, al tiempo que implementaban medidas proteccionistas, y finalmente estaban los que aceptaban el libre cambio. Las grandes corporaciones defendían una mayor liberalización del mercado y desarrollaron una lucha contra la piratería por internet, ya que la innovación tecnológica y la digitalización de la señal sonora, junto con la implantación de internet, habían generado un consumo masivo de productos culturales sin remuneración económica.
Las corporaciones, que eran las más perjudicadas, lo denunciaron como una vulneración de los derechos de autor ${ }^{14}$.

Esto originó un fuerte debate acerca de los derechos de autor entre corporaciones, consumidores y artistas. Las corporaciones consideraban la calidad de los regímenes de derechos de propiedad intelectual fundamentales, dado que era un determinante primordial de los incentivos a la inversión y, por tanto, a la creación de riqueza. Desde las corporaciones se defendió que, cuanto más efectiva fuera la protección de los derechos de propiedad intelectual, tanto más eficiente sería el desarrollo económico. Esta cuestión se convirtió en una de las prioridades en la agenda de la política exterior de los Estados Unidos, ya que el sector industrial mediático estadounidense era uno de los más interesados.

Aparte de las repercusiones económicas, la difusión cultural global produjo otros efectos. El consumo de productos culturales estandarizados y globales representaba una apertura y una diversificación atractivas para aquellos que no podían acceder a ellos por el hecho de su exclusión económica o de la censura. Pero, al mismo tiempo, alimentaba el temor a un empobrecimiento cultural a través de una uniformización cultural de ámbito global (Ritzer, 2007). De hecho, a menudo, en la periferia del sistema determinados grupos sociales percibían la avalancha cultural procedente del centro del sistema como una occidentalización y una forma de agresión que ponía en riesgo sus identidades. No en vano los cambios culturales provocados por la exhaustiva difusión cultural proveniente de las grandes corporaciones cuestionaron valores, costumbres y creencias que parecían sólidamente arraigadas (Gentz y Kramer, 2006).

Hay que tener en cuenta que la cultura es un magma en continuo cambio, no es algo estático e inamovible, sino que sufre variaciones y transformaciones progresivas. El aumento y la aceleración de la circulación de ideas y de valores característicos del proceso de globalización ampliaron de manera considerable la oferta identitaria,

14 A pesar de que en 2010 el mercado de productos y servicios digitales facturó 2.7 billones de euros en todo el mundo. 
con lo cual se favorecieron cada vez más los mestizajes y las hibridaciones. La cultura consiste en un sustrato de lenguas, ideas, valores, creencias, costumbres, códigos, instituciones, obras de arte, rituales, ceremonias, etc. Es indudable que el flujo de comunicaciones puede afectar o modificar algunos de los elementos fundamentales que componen una cultura determinada, pero es muy difícil que la cultura pueda homogeneizarse de una manera intencionada (Palomo, 2008).

La irrupción de una cultura global no debería representar una amenaza para las identidades, siempre y cuando no excluyera la coexistencia con otras formas y prácticas culturales autóctonas. Sin embargo, es obvio que, en el intercambio cultural global, las culturas del centro del sistema partían con ventaja, debido a su dominio económico y tecnológico. Además, la adaptación al proceso de globalización conllevaba inevitablemente una tendencia hacia la homogeneización cultural. Sin embargo, esto no significa que el proceso homogeneizador estuviera completamente controlado por el centro del sistema. Los Gobiernos del centro del sistema no podían inmunizar a su cultura contra las influencias externas, por lo que se trataba de un proceso incontrolable de repercusiones incalculables.

\section{EL PODER BLANDO}

La imposibilidad de controlar el proceso homogeneizador no significa que los actores del sistema internacional renuncien a proponer modelos culturales que puedan ser imitados por el resto, lo cual les dotaría de una ventaja competitiva o les permitiría imponer su voluntad al resto. En la globalización, la industria de la comunicación ha desempeñado el papel clave de aportar los canales a través de los cuales se difunden estos modelos culturales. La industria de la comunicación posee una singularidad que condiciona su funcionamiento. Por un lado, debe atender a su propio mercado de las comunicaciones $y$, por otro, provee el canal a través del cual otros agentes pueden comunicarse con el público.

En las corporaciones, a través de la publicidad y las técnicas de marketing, las corporaciones tratan de generar modelos culturales que motiven al público a consumir sus productos. Por tanto, la publicidad produce modelos culturales que cumplen la función de estimular la necesidad personal de consumo. Se crean necesidades personales que hasta ese momento los individuos no habían tenido, hasta el punto de que se produce una frustración si el individuo no consigue satisfacer estas “necesidades”. Una vez formados y reforzados los gustos del público según los intereses comerciales de las corporaciones, estas dan la vuelta al argumento para justificar sus ofrecimientos con el pretexto de la demanda pública (Schiller, 1976, p. 36). En esta mecánica, los medios de comunicación se han convertido en el soporte principal de la publicidad y en una de las herramientas básicas para la expansión de los mercados (Crusafon, 2012, p. 62).

En las organizaciones no gubernamentales (ONG) también son responsables de la proyección de modelos culturales que se difunden a través de los medios de comunicación. Estos modelos culturales pueden ser considerados como un subproducto que emana directamente de la sociedad civil. Las ONG catalizan estas expresiones culturales y las proyectan de nuevo sobre la sociedad e influyen sobre la opinión pública. La defensa de los derechos humanos, el reclamo de la democracia como sistema político ideal, la defensa del medio ambiente, el reclamo de la igualdad de sexos, etc., son expresiones de la sociedad que las ONG convierten en modelos culturales, los cuales se difunden a través de los medios de comunicación e influyen en la opinión pública. Su favoritismo ella no es nada despreciable y pueden influenciar la acción del Gobierno, pero también complicarla y obstruir sus estrategias.

En los Estados, los gobiernos buscan difundir modelos culturales que ayuden a mantener el statu quo político, económico y social. Por tanto, el complejo mediático sirve de plataforma para que las élites sociales difundan su discurso. Este discurso puede ir dirigido al interior del propio Estado, o en los Estados más potentes, también hacia el exterior. Para un Estado es una forma de proyección de su poder de difundir modelos culturales propios en el ámbito internacional. Cuando los modelos culturales se universalizan, proporcionan importantes resortes de poder y capacidad al Estado que los fomenta, ya sea para establecer normas, ya sea 
instituciones internacionales. A esta forma de ejercer el poder se la denomina "poder blando" (Nye, 2003).

El poder blando se fundamenta en la idea de influenciar la concepción que el otro tiene de su interés, con la intención de que vele por el cumplimiento de los objetivos del que ejerce el poder blando. Estos intereses pueden ser canalizados a través de un conjunto de ideas $\mathrm{y}$ valores bien articulados y proyectados al mundo, por ejemplo mediante programas de intercambio académico, la estandarización de los medios de comunicación de masas o la difusión de sus formas de entretenimiento (Veiga y Mourenza, 2012, p. 163). Por tanto, el poder blando procede en gran parte del sistema de valores que genera la cultura. Estos valores se expresan a través de las manifestaciones culturales y de la política (Nye, 2003, p. 31). Si un Estado logra legitimar su poder a ojos de los demás, hallará menos resistencia para imponer su voluntad.

En los Estados Unidos, como potencia hegemónica, los dirigentes estadounidenses no dudaron un momento en poner a funcionar su potente industria de comunicaciones al servicio de la expansión de su modelo cultural por todo el planeta. De esta forma, las comunicaciones se convirtieron en la punta de lanza del liderazgo estadounidense en la globalización (Schiller, 1976, p. 18). Si el líder tenía una ideología y una cultura atractivas, los demás le seguirán de buen grado. Cuando la organización social y la cultura de los Estados Unidos fueran atractivas al resto del mundo, se reduciría la sensación de vasallaje y amenaza, y por tanto la necesidad de contrarrestarla. El hecho de poseer el apoyo de una masa social crítica portadora de los valores estadounidenses en cualquier lugar del planeta facilitaba la consecución de los intereses estadounidenses.

Panorama I

Sin embargo, esta familiaridad virtual también podía amplificar el malestar con las políticas estadounidenses si decepcionaba las expectativas creadas. La principal consecuencia adversa de la seducción cultural consiste en que del líder cultural se espera algo más. Por ejemplo, las actuaciones egoístas en nombre del interés nacional son mal recibidas en la opinión pública global. En ocasiones, esto limita el campo de maniobra del Gobierno en cuestión. En los Estados Unidos, no hubo excepción, y cuando el Gobierno de G. W. Bush empleó un discurso más nacionalista para reforzar su política exterior, se produjo un desafecto importante en buena parte de la población mundial.

\section{EL CONTROL DE LA INFORMACIÓN}

Las nuevas condiciones tecnológicas han permitido un aumento brutal del volumen de la información en el mundo (Gitlin, 2005). La digitalización que permite mayor almacenamiento de información, los satélites que posibilitan abarcar todo el espacio planetario y las redes cableadas están en el origen de una bajada importante de los costes de la información y un aumento considerable de su capacidad de emisión. La información es ahora inmediata, fluida, continua y accesible a cada vez más público. Esta circulación de la información por medios escritos, televisión e internet ha generado mayor conciencia política y acentúa la porosidad entre el debate político, social, cultural, etc., nacional y internacional. Los agentes no estatales, las ONG y las corporaciones tienen muchas más posibilidades de organizarse y propagar sus ideas, ya que pueden penetrar profundamente en los acervos culturales de las sociedades de todo el mundo (Urgoiti, 2006). En este sentido, los gobiernos de los Estados, las corporaciones y las ONG cada vez recurren más a recursos, como el seguimiento de medios, los sondeos, los expertos en comunicación, los gabinetes de prensa, etc., que les proporcionen habilidad frente a la opinión pública en los discursos de legitimación de sus acciones.

Con el proceso de globalización y la difusión de la información a gran escala, las sociedades han adquirido conciencia de las disparidades existentes en los niveles de bienestar material y los diferentes estilos de vida globales. Esta concienciación puede generar malestar en los más desfavorecidos y motivar movilizaciones en la sociedad. Por tanto, las movilizaciones de las sociedades civiles han ganado en protagonismo e influyen cada vez más en las situaciones políticas. Una consecuencia política directa de esto ha sido la pérdida por parte de los Gobiernos del tradicional control sobre la información relativa a sus propias sociedades. La información se ha hecho transfronteriza y poco dominable para los 
Estados. Los Gobiernos deben tener ahora muy en cuenta a la opinión pública interna y a la internacional.

Como respuesta a este desafío, los Gobiernos han desarrollado sus mecanismos de control sobre las comunicaciones. En el ámbito de las comunicaciones personales, los Gobiernos han desplegado mayores medios y personal dedicados al espionaje de las comunicaciones de organizaciones e individuos. En los Estados democráticos se han relajado las leyes que defendían el derecho a la privacidad como una medida necesaria para garantizar la seguridad. Por ejemplo, en los Estados Unidos la $\mathrm{NSA}^{15}$, la $\mathrm{CIA}^{16}$ y el $\mathrm{FBI}^{17}$ tienen acceso legal a todas las comunicaciones particulares por internet o teléfono móvil si existe la sospecha de un delito. En el ámbito internacional, la red militar de espionaje Echelon, en la que participa el Ejército de los Estados Unidos y otros Estados aliados, monitorea las comunicaciones por internet en todo el mundo.

Con respecto a la difusión de la información a través de los medios de comunicación, los Gobiernos desarrollan actitudes que van desde una ignorancia cada vez menos posible o una censura cada vez más costosa políticamente, hasta posturas de acomodo, de composición, de control de influencia e incluso de manipulación ${ }^{18}$. Solo los Gobiernos totalitarios recurren todavía a una censura total que cada vez se hace más difícil. Los Estados más poderosos buscan encauzar la información de la manera que les sea más beneficiosa o menos dañina, por medio del control de los recursos de que disponen los periodistas en el lugar de la noticia o presionando a las jefaturas de redacción a la hora de difundir la noticia. A este procedimiento se le conoce como autocensura. En este caso, se activa un "dispositivo verificativo", que desde el propio medio de comunicación filtra la información de acuerdo con las prioridades del poder. Sin embargo, pueden haber filtraciones o errores de "verificación" que no pueden evitar que salgan a la luz informaciones no deseadas.

15 National Security Agency.

16 Central Intelligence Agency.

17 Federal Bureau of Investigation.

18 El caso más paradigmático en los últimos años tal vez sea el de la existencia de las armas de destrucción masiva en Irak, pregonada a los cuatro vientos por todos los medios y algunos gobiernos hasta que se demostró la falsedad de la información.
El reforzamiento de las influencias ajenas, sumado a la reducción de los gastos en los medios de comunicación tradicionales, ha generado una pérdida de la calidad de la información que dichos medios suministran. La reducción en los gastos ha provocado despidos masivos de trabajadores, lo cual ha disminuido los controles de calidad internos y, además, ha obligado a los periodistas a cubrir más frentes que antes. El resultado de ambas tendencias: el reforzamiento de las influencias y la pérdida de capacidad en el tratamiento de la información, ha sido el abuso en la utilización de fuentes oficiales y la proliferación de la práctica de repetir las noticias sin contrastarlas entre los propios medios (hasta $68 \%$ de las noticias difundidas por los medios no se contrastan y son tomadas textualmente de otros medios) (Borreguero, 2007, p. 79).

La libertad de prensa constituye otro indicador de la salud de la democracia y del respeto a los derechos humanos en el mundo. La cifra de reporteros secuestrados, encarcelados y asesinados aumenta de año en año. Además, ahora se persigue a los "ciberdisidentes" que son internautas que denuncian cuestiones políticas en los Estados de origen. Estos casos son comunes en Estados autoritarios, como China ${ }^{19}$ e Irán, pero también en sistemas democráticos, como demuestra la persecución al promotor de WikiLeaks, Julian Assange, por parte del Gobierno de los Estados Unidos ${ }^{20}$. Sin embargo, estas medidas represivas internas cada vez son más costosas en términos de prestigio internacional. $\mathrm{El}$ prestigio es ahora más importante incluso que antes en un mundo globalizado donde es necesario encontrar aliados para defender los intereses propios. Por este motivo, gran parte de las pugnas políticas entre los Gobiernos se producen en torno a la creación y destrucción de la credibilidad. No olvidemos que la credibilidad es un recurso crucial y una fuente de poder blando (Nye, 2003, p. 103).

La información en el mundo está casi acaparada por grandes corporaciones que compiten entre sí. La

\footnotetext{
19 Por ejemplo, el Gobierno chino ejerce un férreo control sobre internet. Solo autoriza el ingreso a cuatro redes de acceso internacional, bloquea determinados sitios web y prohíbe los sitios web chinos que difunden noticias procedentes de sitios web extranjeros.

20 El Gobierno de los Estados Unidos también ha intentado asegurar el ciberespacio con controles draconianos en nombre de la seguridad nacional y de la lucha contra el terrorismo o de los derechos de propiedad.
} 
propiedad de los medios de comunicación, como en otras corporaciones, está sometida en la globalización a un proceso de concentración. Se han formado grandes conglomerados corporativos que abarcan la producción y difusión en editoriales, periódicos, radios, cine, televisión, internet, etc., y dominan también las redes de comercialización. Las 10 principales corporaciones mediáticas (comunicación y entretenimiento) según sus ingresos en 2010 eran Sony ${ }^{21}$ (Japón) con 83844 millones de dólares; Walt Disney ${ }^{22}$ (EE.UU.) con 38063 millones de dólares, Comcast ${ }^{23}$ (EE.UU.) con 37937 millones de dólares, Amazon ${ }^{24}$ (EE.UU.) con 34204 millones de dólares, News Corp. ${ }^{25}$ (EE.UU.) con 32778 millones de dólares, Google ${ }^{26}$ (EE.UU.) con 29321 millones de dólares, Time Warner ${ }^{27}$ (EE.UU.) con 26888 millones de dólares, DirecTV ${ }^{28}$ (EE.UU.) con 24102 millones de dólares, Maruhan ${ }^{29}$ (Japón) con 23805 millones de dólares, Bertelsmann ${ }^{30}$ (Alemania) con 21791 millones de dólares (Crusafon, 2012, pp.72-73).

Estas corporaciones abarcan un amplio sector de la comunicación y mantienen estrechos vínculos con

21 Sony es una de las corporaciones más grandes del mundo. Es uno de los fabricantes líder en la electrónica de consumo, el audio y el video profesional, los videojuegos y las tecnologías de la información y la comunicación. También posee canales de televisión como Sony Entertainment Television, AXN, Entertainment Television y Animax.

22 Es la mayor compañía de medios de comunicación y entretenimiento del mundo. Posee parques temáticos y diversos canales de televisión en abierto y por cable, como $\mathrm{ABC}$ y los variados canales infantiles Disney Channel, Disney XD, Disney Junior y Disney Cinemagic.

$23 \mathrm{El}$ principal negocio de Comcast es ser operador de cable y telecomunicaciones, pero en 2009 adquirió NBC-Universal.

24 Amazon es un gigante del comercio electrónico que se ha expandido hacia el sector mediático. Posee Alexa Internet, a9.com, Shopbop, Kongregate, Internet Movie Database (IMDb), Zappos.com, DPreview.com y The Washington Post.

25 News Corporation agrupa en su división editorial importantes cabeceras, como The Sun, The Times, The New York Post, The Daily Telegraph, etc. Su gran salto a los medios audiovisuales lo realizó con Fox, Metromedia, Twientieth Century Fox, National Geographic, Star TV, etc.

Panorama I

26 Está especializada en productos y servicios relacionados con internet, software, dispositivos electrónicos y otras tecnologías. El principal producto de Google es el motor de búsqueda de contenido en internet del mismo nombre, aunque ofrece también otros servicios, como el servicio de correo electrónico Gmail, el servicio de mapas Google Maps y Google Earth y el sitio web de videos YouTube.

27 Es el segundo conglomerado mediático en ganancias por detrás de Disney. Posee New Line Cinema, Time Inc, Turner Broadcasting System, The CW, Warner Bros, Warner Bros Animation, HBO, DC Comics, Cartoon Network Studios y Castle Rock Entertainment.

28 Es un proveedor de servicio de difusión directa por satélite. Transmite televisión digital, incluidos canales de audio y radio por satélite a los Estados Unidos y América Latina.

29 Maruhan gestiona y mantiene una variedad de instalaciones de ocio y se ha ido diversificando hacia el sector mediático.

30 Posee RTL Group, Gruner + Jahr, Prisma, BMG, BMG Music Publishing, Random House, Direct Group, Arvato, etc. otras corporaciones de diferentes sectores ${ }^{31}$, lo cual hace ilusorio que las informaciones generadas por ellas tengan algún criterio de independencia. Por el contrario, están sometidas a un complejo entramado de intereses económicos. Este hecho levanta suspicacias inevitables acerca de la objetividad en la información y del derecho a la información y su control, ya que influyen sobre la opinión pública (Chomsky y Ramonet, 1996). Nadie puede realmente controlar por completo a la opinión pública. Sin embargo, su autonomía es relativa. La opinión pública es un complejo agregado de interacciones de comportamientos sociales individuales y colectivos, articulados de forma fugaz, coyuntural o persistente en el tiempo. No se interesa por lo que los medios de comunicación no muestren y depende de lógicas de captación de audiencia que favorecen lo espectacular. No en vano la publicidad y su técnica de marketing es la que más éxito ha demostrado a la hora de captar la atención de esta opinión pública.

Entre la información difundida cobra especial relevancia la distribución de las noticias de prensa. La información de prensa que difunden los medios de comunicación influye drásticamente sobre la forma en que las sociedades perciben el mundo que les rodea, llegando a alterar su forma de actuar (Quirós y Sierra, 2001). En este sentido, los medios de comunicación se encargan de difundir las noticias "fiables" que desaniman a los disidentes, sean quienes sean, o se crea una impresión de que las condiciones que se van a desarrollar son naturales e inevitables ${ }^{32}$.

Como con la información en general, la distribución de las noticias está muy concentrada globalmente. En la actualidad, las mismas imágenes de las grandes agencias de prensa se difunden de manera permanente con mínimas diferencias en el montaje, los comentarios y la duración. Hay que tener en cuenta que las dos terceras partes de las noticias en el mundo son distribuidas

\footnotetext{
31 Los principales accionistas de las corporaciones mediáticas suelen ser corporaciones financieras.

32 La self fulfilling prophecy (profecía que se autocumple) consiste en predicciones a no muy largo plazo, hechas por expertos económicos, sociales o políticos, del desarrollo que va a seguir la economía, la sociedad o la política. Estas predicciones tienen, con frecuencia, un efecto añadido. No pocas veces influyen, como una retroalimentación, en ese comportamiento que precisamente debían prever, por lo cual crean una especie de predisposición para que las condiciones predichas se autocumplan. Es decir, se trata de una especie de "determinismo prefabricado".
} 
a través de agencias de noticias y que las principales agencias pertenecen al centro del sistema. AP, Reuters, France Press, DPA, ANSA, Press Association y Efe son estadounidenses o europeas, y Kiodo es japonesa. Tan solo Tass (Rusia) y Xinhua (China) entran dentro de la clasificación de las 10 más importantes y pertenecen a Estados de la periferia (Borreguero, 2007, p. 35).

Además de las agencias de prensa, las cadenas globales de noticias que emiten por satélite ocupan un lugar protagonista en la difusión de las noticias. La dimensión global de la distribución de la información sigue dominada por la televisión. Si bien es cierto que internet ha irrumpido con fuerza en la difusión de la información, hay que tener en cuenta que, en gran parte del planeta, el acceso a la red no es habitual, por lo que es mucho más fácil tener acceso a la televisión por satélite.

Las nuevas cadenas globales de noticias, que emiten ininterrumpidamente, irrumpieron con fuerza en la globalización. La pionera fue la CNN de los Estados Unidos que actualmente emite en 10 lenguas diferentes y se dirige a una audiencia de 1000 millones de telespectadores ${ }^{33}$. Durante la guerra del Golfo (1991) contó con el monopolio de la cobertura de los combates y se convirtió en una referencia informativa para los medios de comunicación de todo el mundo. El ejemplo de CNN abrió un amplio campo de competencia internacional. BBC World se adaptó a este nuevo modelo y aportó la veteranía de la gran cadena de TV pública británica. A mediados de la década de 1990, se incorporó una nueva cadena estadounidense, Fox News, que fue ganando importancia con el nuevo siglo.

Por la misma época, también surgieron imitadores desde los países europeos, con financiamiento público, Deutsche Welle en Alemania, France 24 en Francia, etc. Este florecimiento indicaba la voluntad política de los Estados por reforzar su influencia internacional. A partir de mediados de la década de 1990, también se incorporaron nuevas cadenas globales de noticias que no tenían su sede en el centro del sistema, sino en la periferia. En 1996 se fundó la cadena Al-Jazeera en Catar para representar una alternativa a CNN y proporcionar un punto

33 CNN pertenece a la corporación Time Warner desde 1996. de vista de la información no occidental y desde una óptica cultural árabe. El éxito de Al-Jazeera fue rotundo y el paisaje mediático mundial pronto se llenó con otras cadenas por satélite que emitían desde la periferia del sistema, como las cadenas chinas CCTV y CNC World o la cadena rusa Russia Today.

$\mathrm{Y}$ es que, desde 2001, se ha venido produciendo un cambio más amplio de tendencia en el flujo de la información. El flujo, habitualmente dominado por el centro de la periferia, se ha visto alterado y la periferia ha tomado un papel más activo reinterpretando su tradicional papel de receptor pasivo de la información (Crusafon, 2012, p. 76). La prueba de este cambio puede verse en el hecho de que algunos Estados de la periferia están comenzando a consolidarse en el mercado global como exportadores de productos audiovisuales, mientras que las corporaciones del centro del sistema se están viendo obligadas a modificar sus productos para responder a nuevas demandas adaptadas a los gustos locales. Ejemplos claros de esta tendencia son Bollywood o la producción cinematográfica en Hong Kong. Por tanto, en 2010, el panorama de los medios de comunicación en el mundo era mucho más complejo que nunca. Se observan signos de cambio sin precedentes en el flujo de la información en dos direcciones: centro-periferia.

\section{CONCLUSIONES}

Las nuevas tecnologías de la comunicación fueron un factor clave que apuntaló el proceso de globalización. El proceso de globalización fue incentivado por los avances en las comunicaciones que aceleraron las relaciones transnacionales. Aparte de los Estados, las corporaciones y las ONG podían contactar y establecer relaciones con similares o individuos particulares en cualquier parte del mundo sin pasar por el control de los Estados. Sin embargo, la nueva sociedad global de la información redujo las distancias, pero no las anuló. Persistió una gran brecha entre el centro y la periferia del sistema global a la hora de ubicar a los usuarios de las nuevas tecnologías de la información (Mattelart, 1993). El mapa mundial del acceso a las telecomunicaciones delata una geografía con contrastes. En la periferia del sistema está menos generalizado el acceso a las tecnologías, principalmente por la 
carencia de infraestructuras y por los bajos ingresos de la población. Esta situación refuerza la capacidad hegemónica de las potencias del centro del sistema internacional con respecto a los Estados de la periferia del sistema.

Por otro lado, los Estados más poderosos y las grandes corporaciones del sector de las comunicaciones controlan los canales de la comunicación global. En el mismo caso de internet, expresión de la libertad de comunicación, la realidad es que las infraestructuras que acumulan la información están presentes en los grandes núcleos urbanos del centro del sistema global. Estos centros de almacenamiento de datos y servidores permiten establecer las interconexiones de las redes de internet públicas o privadas. La mayoría se hallan en los Estados Unidos, bajo control de sus corporaciones o directamente del Estado (Lasica, 2006). En realidad, internet es una red hipercentralizada de miles de redes, compuesta de rutas y equipamientos interconectados y solo las grandes corporaciones en las sedes de las principales ciudades del mundo poseen los recursos técnicos y la capacidad financiera para la innovación tecnológica y el control de estas costosas redes. De aquí se deduce que las herramientas que brindan las nuevas tecnologías para el ejercicio del poder blando solo están en manos de un grupo reducido de actores internacionales.

La sociedad de la información, nacida al calor de la globalización, si bien ha extendido el acceso a la información, no necesariamente ha fomentado una difuminación del ejercicio del poder blando. Como hemos visto, los actores más poderosos del sistema internacional han sabido reposicionarse en la sociedad de la información para controlar los flujos de información y poder ejercer, con igual o mayor efectividad, el poder blando. De esta manera, pretenden no ceder sus ventajas comparativas que les permiten ejercer una posición hegemónica sobre el resto de manera continuada.

Lo que sí es innegable es que la irrupción de la sociedad de la información global y las nuevas tecnologías han abierto una nueva dimensión en el ejercicio del poder blando. La disputa entre los principales actores del sistema internacional por posicionarse en los nuevos espacios abiertos a la comunicación puede protago- en los siguientes años. Esta disputa se desenvolvería en un ambiente de mayor competitividad causado por la prolongación de la crisis global sistémica.

\section{REFERENCIAS BIBLIOGRÁFICAS}

1. Arrighi, G. (2007). Adam Smith en Pekin. Akal: Madrid.

2. Barbier, F. y Bertho, C. (1996). Historia de los medios. Buenos Aires: Colihue.

3. Barker, C. (2003). Televisión, globalización e identidades culturales. Barcelona: Paidós.

4. Borreguero, R. (2007). Comunicación y poder. Madrid: Universitas.

5. Castells, M. (2000). La era de la información: la sociedad red (vol. I). Madrid: Alianza.

6. Castells, M. (2001a). La era de la información: el poder de la identidad (vol. II). Madrid: Alianza.

7. Castells, M. (2001b). La era de la información: fin de milenio (vol. III). Madrid: Alianza.

8. Chomsky, N. y Ramonet, I. (1996). Cómo nos venden la moto (Vol.2). Icaria Editorial.

9. Collon, M. (1996). ; Ojo con los media! Guipúzcoa: Ediciones EPO/Hiru.

10. Crusafon, C. (2012). La nueva era mediática. Barcelona: Bosch.

11. Gentz, N. y Kramer, S. (eds.) (2006). Globalization, cultural identities and media representations. Albany: State University New York.

12. Gitlin, T. (2005). Enfermos de información. Barcelona: Paidós.

13. Harvey, D. (2007). El nuevo imperialismo. Madrid: Akal.

14. Held, D. y McGrew, A. (2011). Globalización/ antigloblalización. Barcelona: Paidós.

15. Kishan, D. (2009). Internationalizing media studies. Nueva York: Routledge.

16. Lasica, J. D. (2006). Darknet. Madrid: Nowtilus.

17. Mattelart, A. (1993). La comunicación mundo. Madrid: Fundesco. 
$\mid \begin{aligned} & \text { El poder } \\ & \text { blando en la } \\ & \text { globalización: }\end{aligned}$

22. Quirós, F. y Sierra, F. (coord.) (2001).

Comunicación, globalización y democracia. Sevilla: Comunicación Social.

23. Ramonet, I. (1997). Un mundo sin rumbo. Madrid: Debate.

24. Ritzer, G. (coord.) (2007). Los tentáculos de la McDonaldización. Madrid: Popular.

25. Sassen, S. (2010). Una sociología de la globalización. Buenos Aires: Katz.

26. Schiller, H. I. (1996). Aviso para navegantes.

Barcelona: Icaria.

27. Schiller, H. I. (1976). Comunicación de masas e imperialismo yanqui. Barcelona: Gustavo Gili.

28. Sparks, C. (2009). Globalization, development and the mass media. Londres: SAGE.

29. Urgoiti, C.J. (2006). Mundialización, comunicación y politica. Madrid: Fragua.

30. Veiga, F. y Mourenza, A. (2012). El retorno de Eurasia 1991-2011. Barcelona: Península.
18. Mattelart, A. (1998). La mundialización de la
comunicación. Barcelona: Paidós.
19. Nye, J. S. (2003). La paradoja del poder norteame-
ricano. Madrid: Santillana.
20. Palomo, A. (2008). La crisis de los valores en la
globalización. Saarbrucken: VDM Verlag Dr.
Müller.
21. Palomo, A. (2012). Apuntes teóricos para el
estudio de la Globalización desde la perspectiva
de las relaciones internacionales. Confines, 8 ,
69-109.
18. Mattelart, A. (1998). La mundialización de la
comunicación. Barcelona: Paidós.
19. Nye, J. S. (2003). La paradoja del poder norteame-
ricano. Madrid: Santillana.
20. Palomo, A. (2008). La crisis de los valores en la
globalización. Saarbrucken: VDM Verlag Dr.
Müller.
21. Palomo, A. (2012). Apuntes teóricos para el
estudio de la Globalización desde la perspectiva
de las relaciones internacionales. Confines, 8 ,
69-109.
18. Mattelart, A. (1998). La mundialización de la
comunicación. Barcelona: Paidós.
19. Nye, J. S. (2003). La paradoja del poder norteame-
ricano. Madrid: Santillana.
20. Palomo, A. (2008). La crisis de los valores en la
globalización. Saarbrucken: VDM Verlag Dr.
Müller.
21. Palomo, A. (2012). Apuntes teóricos para el
estudio de la Globalización desde la perspectiva
de las relaciones internacionales. Confines, 8 ,
69-109.
18. Mattelart, A. (1998). La mundialización de la
comunicación. Barcelona: Paidós.
19. Nye, J. S. (2003). La paradoja del poder norteame-
ricano. Madrid: Santillana.
20. Palomo, A. (2008). La crisis de los valores en la
globalización. Saarbrucken: VDM Verlag Dr.
Müller.
21. Palomo, A. (2012). Apuntes teóricos para el
estudio de la Globalización desde la perspectiva
de las relaciones internacionales. Confines, 8 ,
69-109.
18. Mattelart, A. (1998). La mundialización de la
comunicación. Barcelona: Paidós.
19. Nye, J. S. (2003). La paradoja del poder norteame-
ricano. Madrid: Santillana.
20. Palomo, A. (2008). La crisis de los valores en la
globalización. Saarbrucken: VDM Verlag Dr.
Müller.
21. Palomo, A. (2012). Apuntes teóricos para el
estudio de la Globalización desde la perspectiva
de las relaciones internacionales. Confines, 8 ,
69-109.
18. Mattelart, A. (1998). La mundialización de la
comunicación. Barcelona: Paidós.
19. Nye, J. S. (2003). La paradoja del poder norteame-
ricano. Madrid: Santillana.
20. Palomo, A. (2008). La crisis de los valores en la
globalización. Saarbrucken: VDM Verlag Dr.
Müller.
21. Palomo, A. (2012). Apuntes teóricos para el
estudio de la Globalización desde la perspectiva
de las relaciones internacionales. Confines, 8 ,
69-109.
18. Mattelart, A. (1998). La mundialización de la
comunicación. Barcelona: Paidós.
19. Nye, J. S. (2003). La paradoja del poder norteame-
ricano. Madrid: Santillana.
20. Palomo, A. (2008). La crisis de los valores en la
globalización. Saarbrucken: VDM Verlag Dr.
Müller.
21. Palomo, A. (2012). Apuntes teóricos para el
estudio de la Globalización desde la perspectiva
de las relaciones internacionales. Confines, 8 ,
69-109.
18. Mattelart, A. (1998). La mundialización de la
comunicación. Barcelona: Paidós.
19. Nye, J. S. (2003). La paradoja del poder norteame-
ricano. Madrid: Santillana.
20. Palomo, A. (2008). La crisis de los valores en la
globalización. Saarbrucken: VDM Verlag Dr.
Müller.
21. Palomo, A. (2012). Apuntes teóricos para el
estudio de la Globalización desde la perspectiva
de las relaciones internacionales. Confines, 8 ,
69-109.
18. Mattelart, A. (1998). La mundialización de la
comunicación. Barcelona: Paidós.
19. Nye, J. S. (2003). La paradoja del poder norteame-
ricano. Madrid: Santillana.
20. Palomo, A. (2008). La crisis de los valores en la
globalización. Saarbrucken: VDM Verlag Dr.
Müller.
21. Palomo, A. (2012). Apuntes teóricos para el
estudio de la Globalización desde la perspectiva
de las relaciones internacionales. Confines, 8 ,
69-109.
18. Mattelart, A. (1998). La mundialización de la
comunicación. Barcelona: Paidós.
19. Nye, J. S. (2003). La paradoja del poder norteame-
ricano. Madrid: Santillana.
20. Palomo, A. (2008). La crisis de los valores en la
globalización. Saarbrucken: VDM Verlag Dr.
Müller.
21. Palomo, A. (2012). Apuntes teóricos para el
estudio de la Globalización desde la perspectiva
de las relaciones internacionales. Confines, 8 ,
69-109.
18. Mattelart, A. (1998). La mundialización de la
comunicación. Barcelona: Paidós.
19. Nye, J. S. (2003). La paradoja del poder norteame-
ricano. Madrid: Santillana.
20. Palomo, A. (2008). La crisis de los valores en la
globalización. Saarbrucken: VDM Verlag Dr.
Müller.
21. Palomo, A. (2012). Apuntes teóricos para el
estudio de la Globalización desde la perspectiva
de las relaciones internacionales. Confines, 8 ,
69-109.

